\title{
Direct and indirect costs incurred by Australian living kidney donors
}

Authors: Lianne Barnieh ${ }^{1}$, John Kanellis², Stephen McDonald ${ }^{3}$, Jennifer Arnold1, Jessica M. Sontrop ${ }^{4}$, Meaghan Cuerden 1 , Scott Klarenbach5, Amit X. Garg1,4, and Neil

Boudville $^{6}$ for the Donor Nephrectomy Outcomes Research (DONOR) Network

\section{Affiliations:}

1. Division of Nephrology, Western University, London, Ontario, Canada

2. Department of Nephrology, Monash Health and Centre for Inflammatory Diseases, Department of Medicine, Monash University

3. Central Northern Adelaide Renal and Transplantation Service, Royal Adelaide Hospital, Adelaide, Australia

4. Department of Epidemiology and Biostatistics, Western University, London, Ontario, Canada

5. Department of Medicine, University of Alberta

6. Medical School, Faculty of Medicine, Dentistry and Health Sciences, University of Western Australia

Short Title: Costs incurred by living kidney donors

\section{Corresponding author:}

Neil Boudville

University of Western Australia

Harry Perkins Institute of Medical Research

$2^{\text {nd }}$ Floor, School of Medicine

QEII Campus Nedlands

WA Australia 6009

Tel - 61-8-6457-3333

Email - neil.boudville@uwa.edu.au

\section{ABSTRACT}

Aim: To describe the direct and indirect costs incurred by Australian living kidney donors.

This article has been accepted for publication and undergone full peer review but has not been through the copyediting, typesetting, pagination and proofreading process, which may lead to differences between this version and the Version of Record. Please cite this article as doi: 10.1111/nep.13205 
Methods: We studied 55 living kidney donors from 3 centres in Perth, Australia and 1 centre in Melbourne, Australia (2010-2014); 49 donors provided information on expenses incurred during the donor evaluation period and up to 3 months after donation. We used a micro-costing approach to measure and value the units of resources consumed. Expenses were grouped as direct costs (ground and air travel, accommodation, and prescription medications) and indirect costs (lost wages and lost productivity). We standardized costs to the year 2016 in Australian dollars.

Results: The most common direct costs were for ground travel (100\%), parking (76\%), and postdonation pain medications or antibiotics (73\%). The highest direct costs were for air travel (median \$1,986 [3 donors]) and ground travel (median \$459 [49 donors]). Donors also reported lost wages (median \$9,891 [37 donors]). The inability to perform household activities or care for dependants were reported by 32 (65\%) and 23 (47\%) donors. Total direct costs averaged \$1,682 per donor (median \$806 among 49 donors). Total indirect costs averaged \$7,249 per donor (median \$7,273 among 49 donors). Total direct and indirect costs averaged \$8,932 per donor (median \$7,963 among 49 donors).

Conclusion: Many Australian living kidney donors incur substantial costs during the donation process. Our findings inform the continued development of policies and programs designed to minimize costs incurred by living kidney donors.

Key Words: Economics; Health expenditures; Kidney transplantation; Living donors 


\section{INTRODUCTION}

The incidence of end-stage kidney disease (ESKD) continues to increase worldwide, and transplantation remains the best treatment option. A kidney transplanted from a living donor has the added benefit of allowing recipients to bypass the waiting list for deceased-donor organs, with many recipients gaining more than 10 years of life expectancy.(1,2) Moreover, every year living with a transplant versus treating kidney disease with dialysis saves the health care system approximately $\$ 100,000$ per patient. $(3,4)$

While living kidney donation is considered safe from a medical perspective,(5) many donors incur substantial financial expenses during the donation process. Current estimates suggest that over $90 \%$ of donors incur expenses as a result of donation, including direct costs (e.g. expenses for traveling to and from the evaluation center) and indirect costs (e.g. lost income for time off work to heal from donation).(6,7) A recent Canadian study estimated that while the total average cost incurred by living kidney donors was \$CAD3,268, one third of living kidney donors incurred more than \$CAD3,000 in out of pocket costs, and 15\% of donors incurred costs that exceeded \$CAD8,000.(8) To reduce the financial burden of living kidney donation, many jurisdictions have introduced reimbursement programs that cover donation-related expenses for donors.(9-11)

In Australia, rates of living donor kidney transplantation have decreased by 32\% since 2008 and many prospective donors cite financial concerns as a top reason for not proceeding with donation.(12,13) Yet, despite being essential to guide informed consent processes and fair reimbursement programs, donor expenses remain poorly understood.(14) We undertook this study to describe and quantify the costs borne by living kidney donors in Australia. As part of an ongoing multicentre study examining the medical, financial, and psychological implications of 
living kidney donation, we estimated the direct and indirect costs incurred by living kidney donors in Australia between 2010 and 2014.

\section{METHODS}

\section{Design, setting and population}

Data for this study were obtained from an ongoing multicentre prospective cohort study examining the medical, financial, and psychological implications of living kidney donation. Participants (1,042 living kidney donors and 400 healthy matched non-donors) were enrolled across Canada (12 centres) and Australia (5 centres) between 2009 and 2014. The results presented here are for the sub-set of Australian donors enrolled between 2010 and 2014; results for Canadian donors will be presented separately. All donors who participated in this study had been approved by their local nephrology team to donate a kidney, were enrolled prior to donation, were 18 years of age or older, and were able to communicate in English or French.

\section{Costing methods and measures}

We used a micro-costing approach and measured units of resources consumed and assignment of a cost per unit (e.g. distance traveled and cost per $\mathrm{km}$ ) to allow for portability and comparison across jurisdictions. Detailed costing methods are provided in Appendix A.

Major cost categories relevant to living donors were identified through a systematic review of the relevant literature(15) in conjunction with consultation of healthcare professionals in transplantation (figure 1). Expenses were grouped into direct and indirect costs. As detailed in Appendix A, direct costs included resources consumed as a result of donating a kidney, regardless of whether a direct monetary transaction occurred; direct costs included ground and air travel, accommodation, and prescription medications. Indirect costs included lost wages, use 
of paid time off or sick leave, and lost productivity (household/domestic activities and caring for dependents).

As a final step, we valued the various resources collected. Workforce productivity was valued using Australian state-specific average wage rates. Other resources were assigned a unit cost using conventional costing techniques with relevant Australian estimates. Out-of-pocket costs were reported as total costs rather than costs per episode (e.g. total cost of parking versus cost per parking stay). Costs are reported in 2016 Australian dollars (1 Australian dollar = \$0.78 USD as of October 15, 2017). Costs were standardized to the year 2016 from the year in which they were reported using the consumer price index (source:

http://www.abs.gov.au/ausstats/abs@.nsf/mf/6401.0)

\section{Data collection}

At study entry, participants underwent a physical exam and completed a standardized survey with questions on sociodemographic characteristics and health history. Three months after donation, participants completed mailed surveys with questions on expenses incurred during the donor evaluation period, the perioperative period, and the first three months after donation. This timeframe was chosen because most expenses related to donation occur within three months of surgery, and the accuracy of recalling information during this timeframe has an interclass coefficient greater than 0.80.(16) Multiple attempts were made to contact donors (by phone, mail or e-mail) about missing or discrepant data.

\section{Statistical analysis}

Total expenses within cost categories were summarized as follows: (1) using the median and interquartile range of costs for only those donors who reported having the expense, and (2) using 
the mean for all donors (including those who did not report having the expense or using the resource). Analyses were conducted using Stata Release 11.2 (StataCorp LP, College Station, TX).

\section{RESULTS}

Between 2010 and 2014, we enrolled 55 living kidney donors across Australia from three units in Perth, and one unit in Melbourne. Of 55 donors, 49 (89\%) completed the costing questionnaire at the 3-month assessment. Characteristics of 49 donors at the time of donation are shown in Table 1. Donors were an average age of 54 years and $90 \%$ were white; $33 \%$ donated to a recipient they were emotionally related to and $41 \%$ donated to a genetically related recipient. All nephrectomies took place between 2010 and 2014.

Direct costs (travel, accommodation, and medication) are summarized in Table 2. The most common direct costs reported by donors included ground travel (100\% [49 donors]), parking (76\% [37 donors]), and post-donation pain medication or antibiotics (73\% [36 donors]). The highest direct costs were for air travel (median \$1,986 [3 donors]), ground travel (median \$459 [49 donors]), and non-hospital accommodation (median \$383 [4 donors]). When averaged across all 49 donors, the total direct costs averaged \$1,682 per donor (median \$806 [49 donors]) (Table 3).

Indirect costs (lost wages and lost productivity) are summarized in Table 2. Lost income was reported by 37 donors (76\%): the median number of days off work was 30 and the median amount of lost income was $\$ 9,891$. Lost productivity was defined as being unable to perform household activities or care for dependants. While these indirect costs were reported by 32 (65\%) 
and 23 (47\%) donors, respectively, reported costs were minimal (median $\$ 0$ for each category). When averaged across all 49 donors, total indirect costs, including lost income, amounted to an average of $\$ 7,249$ per donor (median $\$ 7,273$ [49 donors]). When lost income was excluded, total indirect costs amounted to an average of $\$ 46$ per donor (median $\$ 0$ [49 donors]).

Total direct and indirect costs averaged \$8,932 per donor (median \$7,963 among 49 donors). The distribution of direct and indirect costs is presented in Figure 2. While 65\% of donors incurred less than $\$ 1,000$ in direct costs, $47 \%$ of donors reported more than $\$ 8,000$ in indirect costs.

\section{INTERPRETATION}

To our knowledge, this is the first study to prospectively evaluate the financial costs incurred by living kidney donors in Australia. All 49 donors in our study incurred direct costs and over one third incurred indirect costs. Total direct and indirect costs averaged \$8,932 per donor, and 10\% of donors incurred costs above $\$ 15,000$, which represents approximately twelve weeks of average weekly earnings in Australia.(17)

Our study confirms that many living kidney donors in Australia incur substantial expenses as result of donating a kidney. Though the recent decrease observed in living donor kidney transplantation aligns with that observed in other countries, an examination of the Australia and New Zealand Dialysis and Transplant Registry found that compared with the lowest socioeconomic disadvantaged quartile, patients from the most advantaged quartile were more likely to receive a living donor kidney transplantation, a disparity not observed in cadaveric donation.(18) This disparity could possibly be explained by the real or perceived financial stress of donating a kidney.(6,7,18) The financial losses of living kidney donors are further 
compounded by the fact that a considerable proportion of living donor kidney transplantations occur between spouses ( $>25 \%$ in Australia), and any financial burden may be increased due to financial consequences of the chronic illness of ESKD. Many recipients have modest median household incomes that are similar to donors' household incomes, limiting the ability of the recipient to aid the donor in covering those expenses.(13)

During the course of this study, the Australian Department of Health piloted the Supporting Leave for Living Organ Donors program (commenced July 1, 2013). This national program reimburses employers who provide leave or ex gratia payments to employees who undergo kidney donation. Reimbursement was set at the national minimum wage (2016: $\$ 672.70$ per week) for up to six weeks leave, providing a maximum lost wages reimbursement equal to $\$ 4,036.20$, which is well below the median lost wages reported by donors in this study $(\$ 7,273)$. In response to the evaluation of the pilot program showing that the average amount of time taken off work for donation was 8.7 weeks, the government extended the reimbursement period to up to nine weeks of lost wages (start date July 1, 2015). At the minimum wage level, this means donors would receive a maximum of $\$ 6,054.30$. Although these programs aid in offsetting direct costs, they still do not account for the totality of lost wages, which represents the largest cost burden for many living kidney donors.(15,19,20)

In July 2006, the Western Australia Country Health Service instituted a Travel Reimbursement scheme for donors living in rural areas, providing a daily rate of $\$ 220.30$ to cover some expenses for travel to and accommodation in Perth. Policies for reimbursing living donors are continuing to evolve, as evidence builds around the financial burden of donating a kidney. The Department of Health in Australia has changed the Supporting Living Organ Donors Program as of July 1, 2017, to include the reimbursement of out-of-pocket expenses of up to $\$ 1,000$ (including 
accommodation, economy airfares, public transport, car hire, parking, petrol and road tolls). Our data suggests that this addition would meet the direct costs of $65 \%$ of living kidney donors.

Other factors need to be considered when developing a living donor reimbursement policy. In particular, it is important to acknowledge whether an employee's benefits cover lost wages, and the type of work the donor engages in, which dictates the type of leave available for workup and recovery. For example, manual labourers may require more time for recovery before being able to return to normal work activities. Reimbursement programs may seek to tailor reimbursement to the type of donor instead of creating a "one size fits all" approach to the financial burden living donors may face. As evidenced herein, regardless of the type of employment, many living kidney donors still lack a consistent way to get paid during their recovery time. McGrath, who undertook a qualitative study on the financial impact of donating a kidney among Australians, reports provided the following statement from a donor on the economic consequences of living kidney donation: “...the average person could not possibly do it.”(7) Another study found that the major concern related to living donation was time off work during recovery.(6)

There is a growing body of evidence describing the direct and indirect costs to donors. A prospective Canadian study found that one third of donors incurred out-of-pocket costs in excess of $\$ 3,000 \mathrm{CAD}$ and $15 \%$ incurred out-of-pocket costs in excess of $\$ 8,000 \mathrm{CAD}$. A retrospective study in the United States found that $20 \%$ of donors reported that donating a kidney caused financial burden and nearly $20 \%$ of donors took unpaid work.(21) Rodrigue et al found that lost wages comprised $60 \%$ of total costs to living kidney donors, echoing the findings in the Australian setting.(22) 


\section{LIMITATIONS}

Our study has limitations. We relied on self-reported data from participants. To minimize recall error, we collected costing data three months after donation(16), and, where possible, asked for information on units of resources consumed rather than only out-of-pocket expenses, This method minimizes the participant burden (and error) of calculating out-of-pocket costs and also enables comparisons across jurisdictions. Although we used broad inclusion criteria, the sample size for this study was small. The $95 \%$ confidence interval of most of our estimates spanned more than $\$ 1,500$ dollars. To examine the potential for selection bias, we examined whether any key differences existed between our participants and the larger population of Australian donors. We found that our participants were slightly older (54 versus 49 years of age), but were similar on gender, race, and health status.(14) Also, Australia is a large country, and although participants were mostly from the Perth area, they could have donated in another jurisdiction, as reflected by the round trip air travel. We also did not consider medical costs in this study. Although Australia has a private health care system, most transplant units have donors evaluated in the public system, thereby eliminating any medical costs not included in the study (for example, laboratory work). It should be noted that wage rates used in this study were averages. Donors with higher income would have incurred higher loss of income, but would have suffered less financial burden given their higher socio-economic status. Finally, the financial considerations for living kidney donors goes beyond what was examined in this study, for example, the ability to obtain life insurance.(23) While other studies have demonstrated that a donor's ability to obtain life insurance is similar to non-donors, this question has not yet been examined in Australia.

\section{CONCLUSIONS}


Many living kidney donors in Australia incur substantial expenses as result of donating a kidney. Our study supports the need for reimbursement programs to reduce the economic consequences of living donation, particularly for donors where the process of living kidney donation is a significant financial burden. Further studies examining the impact on costs and consequences to living donation can help inform policy and demonstrate if it is a factor influencing the recent decline in living kidney donation rates seen in Australia and around the world. 
Table 1. Characteristics of 49 Australian living kidney donors at the time of donation

\begin{tabular}{|c|c|c|}
\hline & $\begin{array}{c}\text { Responders } \\
n=49\end{array}$ & $\begin{array}{c}\text { Non-responders } \\
n=6\end{array}$ \\
\hline Characteristic & N (\%) or mean (range) & N (\%) or mean (range) \\
\hline Age, years & $54(30-70)$ & $52(42-65)$ \\
\hline Women & 27 (55\%) & $6(100 \%)$ \\
\hline Caucasian & $44(90 \%)$ & $4(67 \%)$ \\
\hline \multicolumn{3}{|l|}{ Year of surgery } \\
\hline 2010 & $5(10 \%)$ & 0 \\
\hline 2011 & $15(31 \%)$ & $1(17 \%)$ \\
\hline 2012 & 7 (14\%) & 0 \\
\hline 2013 & $12(25 \%)$ & $3(50 \%)$ \\
\hline 2014 & $10(20 \%)$ & $2(33 \%)$ \\
\hline \multicolumn{3}{|l|}{ Marital status, n (\%) ${ }^{1}$} \\
\hline Married / common law & $46(94 \%)$ & $6(100 \%)$ \\
\hline Separated or divorced & $1(2 \%)$ & 0 \\
\hline Never married & $2(4 \%)$ & 0 \\
\hline \multicolumn{3}{|l|}{ Donor relationship with recipient } \\
\hline Emotionally related & $16(33 \%)$ & $4(67 \%)$ \\
\hline Genetically related & $20(41 \%)$ & $1(17 \%)$ \\
\hline Anonymous/altruistic & $13(27 \%)$ & $1(17 \%)$ \\
\hline \multicolumn{3}{|l|}{ Occupational status } \\
\hline Employed (full or part-time) & $42(86 \%)$ & $4(67 \%)$ \\
\hline Retired & $6(12 \%)$ & 0 \\
\hline Other & $1(2.0 \%)$ & $2(33 \%)$ \\
\hline \multicolumn{3}{|c|}{ Highest level of completed education } \\
\hline High school & $25(51 \%)$ & $3(50 \%)$ \\
\hline Trade school or college & $15(31 \%)$ & $1(17 \%)$ \\
\hline University & $9(18 \%)$ & $2(33 \%)$ \\
\hline \multicolumn{3}{|l|}{ Insurance* } \\
\hline Life insurance & $24(50 \%)$ & 0 \\
\hline Disability insurance & $16(33 \%)$ & 0 \\
\hline Private medical insurance & $36(73 \%)$ & $3(50 \%)$ \\
\hline \multicolumn{3}{|l|}{ Comorbidities } \\
\hline Hypertension & $20(41 \%)$ & $4(67 \%)$ \\
\hline
\end{tabular}

*At time of donation, donor held one or more of these policies. 
Table 2. Donation-related costs incurred by 49 living kidney donors, Australia (2010-2014), 2016 AUD\$

\begin{tabular}{|c|c|c|c|c|c|c|c|c|c|}
\hline & \multirow{2}{*}{$\begin{array}{l}\text { Cost } \\
\text { category }\end{array}$} & \multirow[b]{2}{*}{ Description } & \multirow[b]{2}{*}{ Units } & \multicolumn{5}{|c|}{ Summary data for donors who reported having the specified cost ${ }^{1}$} & \multirow{2}{*}{$\begin{array}{c}\text { Average cost } \\
\text { across } 49 \\
\text { donors }^{2} \text { (SD) }\end{array}$} \\
\hline & & & & $\begin{array}{l}\text { Number of } \\
\text { donors }\end{array}$ & $\begin{array}{c}\text { Median } \\
\text { units (IQR) }\end{array}$ & $\begin{array}{l}\text { Max } \\
\text { units }\end{array}$ & $\begin{array}{l}\text { Median cost } \\
\quad \text { (IQR) }\end{array}$ & $\begin{array}{c}\text { Max } \\
\text { cost }\end{array}$ & \\
\hline \multirow{7}{*}{$\begin{array}{l}\text { Direct } \\
\text { costs }\end{array}$} & \multirow{3}{*}{ Travel } & Ground travel & $\begin{array}{l}\text { Return } \\
\text { trips }\end{array}$ & $49(100 \%)$ & $\begin{array}{c}15 \\
(10,20)\end{array}$ & 60 & $\begin{array}{c}\$ 459 \\
(322,958)\end{array}$ & $\$ 9,979$ & $\$ 1,072(1,654)$ \\
\hline & & Air travel & $\begin{array}{l}\text { Return } \\
\text { trips }\end{array}$ & $3(6.1 \%)$ & $\begin{array}{c}3 \\
(1,3)\end{array}$ & 3 & $\begin{array}{c}\$ 1,986 \\
(345,2,040)\end{array}$ & $\$ 2,040$ & $\$ 89(404)$ \\
\hline & & Parking 3 & $\begin{array}{l}\text { Days } \\
\text { parked }\end{array}$ & $37(76 \%)$ & $\begin{array}{c}12 \\
(6,20)\end{array}$ & 80 & $\begin{array}{c}\$ 66 \\
(28,124)\end{array}$ & $\$ 850$ & $\$ 104$ (152) \\
\hline & \multirow{3}{*}{ Accommodation } & Family \& friends ${ }^{3}$ & Nights & $10(20 \%)$ & $\begin{array}{c}9 \\
(2,14)\end{array}$ & 25 & $\begin{array}{c}\$ 263 \\
(96,1,033)\end{array}$ & $\$ 5,285$ & $\$ 178(779)$ \\
\hline & & Non-hospital paid & Nights & $4(8.2 \%)$ & $\begin{array}{c}2.5 \\
(1.5,4.5)\end{array}$ & 6 & $\begin{array}{c}\$ 383 \\
(260,630)\end{array}$ & $\$ 840$ & $\$ 36$ (142) \\
\hline & & Hospital $^{3}$ & Nights & 15 (31\%) & $\begin{array}{c}4 \\
(3,4)\end{array}$ & 7 & $\begin{array}{c}\$ 44 \\
(22,114)\end{array}$ & $\$ 7,434$ & $\$ 176(1,060)$ \\
\hline & Medication & $\begin{array}{l}\text { Pain medication or } \\
\text { antibiotics }^{3}\end{array}$ & $\begin{array}{l}\text { Yes or } \\
\text { no }\end{array}$ & $36(73 \%)^{5}$ & N/A & & $\begin{array}{c}\$ 263 \\
(96,1,033)\end{array}$ & $\$ 310$ & $\$ 27(61)$ \\
\hline \multirow{3}{*}{$\begin{array}{l}\text { Indirect } \\
\text { costs }\end{array}$} & Lost wages & $\begin{array}{l}\text { Days unable to work } \\
\text { (if employed) }^{5}\end{array}$ & Days & 37 (76\%) & $\begin{array}{c}30 \\
(15,35) \\
\end{array}$ & 120 & $\begin{array}{c}\$ 9,891 \\
(5,096,11,636) \\
\end{array}$ & $\$ 34,908$ & $\$ 7,204(6,795)$ \\
\hline & \multirow{2}{*}{$\begin{array}{l}\text { Lost } \\
\text { productivity }\end{array}$} & $\begin{array}{l}\text { Unable to perform } \\
\text { household activities }^{3}\end{array}$ & Days & 32 (65\%) & $\begin{array}{c}14 \\
(6,21)\end{array}$ & 60 & $\begin{array}{c}\$ 0 \\
(0,0)\end{array}$ & $\$ 1,274$ & $\$ 35$ (186) \\
\hline & & $\begin{array}{l}\text { Unable to care for } \\
\text { dependants }^{3}\end{array}$ & Days & 23 (47\%) & $\begin{array}{c}10 \\
(5,21)\end{array}$ & 60 & $\begin{array}{c}\$ 0 \\
(0,0)\end{array}$ & $\$ 310$ & $\$ 11(54)$ \\
\hline
\end{tabular}

Abbreviations: AUD, Australian dollar rates; IQR, interquartile range; N/A, not applicable; SD, standard deviation.

${ }^{1}$ Considers only those donors who reported having the expense.

${ }^{2}$ Total cost averaged over all 49 donors (including those who did not report having this expense, which was considered $\$ 0$ ).

${ }^{3}$ Self-reported costs (not micro-costed).

${ }^{4}$ One donor missing cost; mean imputed.

${ }^{5}$ Assumed to be paid work days. 
Table 3. Total direct and indirect costs incurred by 49 living kidney donors, 2016 AUD\$

\begin{tabular}{lccc}
\hline & Median (IQR) & Max & $\begin{array}{c}\text { Average cost } \\
\text { across 49 donors } \\
\text { (SD) }\end{array}$ \\
\hline Direct costs & $\$ 806(436,1,291)$ & $\$ 15,637$ & $\$ 1,682(2,745)$ \\
\hline Indirect costs & $\$ 0(0,0)$ & & \\
\hline Excluding lost wages & $\$ 1,274$ & $\$ 46(204)$ \\
$\quad$ Including lost wages & $\$ 7,273(1,359,10,192)$ & $\$ 36,182$ & $\$ 7,249(6,903)$ \\
\hline $\begin{array}{l}\text { Total costs, direct and indirect } \\
\text { (including lost wages) }\end{array}$ & $\$ 7,963(3,724,12,265)$ & $\$ 37,139$ & $\$ 8,932(7,281)$ \\
\hline
\end{tabular}

Abbreviations: AUD, 2016 Australian dollars; IQR, interquartile range; SD, standard deviation. 
Figure 1. Method of estimating direct and indirect costs for living donors

Figure 2. Proportion of direct, indirect and total costs incurred by living donors ( $n=49 *)$, AUD\$ 


\section{ACKNOWLEDGEMNTS}

Neil Boudville was funded by the Raine Medical Research Foundation and the National Health and Medical Research Council 


\section{REFERENCES}

1. Wolfe RA, Ashby VB, Milford EL, et al. Comparison of mortality in all patients on dialysis, patients on dialysis awaiting transplantation, and recipients of a first cadaveric transplant. New Engl J Med. 1999;341(23):1725-30.

2. Port FK, Wolfe RA, Mauger EA, Berling DP, Jiang K. Comparison of survival probabilities for dialysis patients vs cadaveric renal transplant recipients. JAMA. 1993;270(11):1339-43.

3. Laupacis A, Keown P, Pus N, Krueger H, Ferguson B, Wong C, et al. A study of the quality of life and cost-utility of renal transplantation. Kidney Int. 1996/07/01. 1996;50(1):235-42.

4. Held PJ, McCormick F, Ojo A, Roberts JP. A Cost-Benefit Analysis of Government Compensation of Kidney Donors. Am J Transplant. 2016 Mar;16(3):877-85.

5. Johnson EM, Anderson JK, Jacobs C, Suh G, Humar A, Suhr BD, et al. Long-term followup of living kidney donors: quality of life after donation. Transplantation. 1999 Mar;67(5):717-21.

6. Cuesta-Briand B, Wray N, Boudville N. The Cost of Organ Donation: Potential Living Kidney Donors’ Perspectives. Health Soc Work. 2015 Nov;40(4):307-15.

7. McGrath P, Holewa H. "It”s a regional thing': financial impact of renal transplantation on live donors. Rural Remote Heal. 2012/11/07. 2012;12:2144.

8. Nesrallah GE, Mustafa RA, Clark WF, Bass A, Barnieh L, Hemmelgarn BR, et al. Canadian Society of Nephrology 2014 clinical practice guideline for timing the initiation of chronic dialysis. CMAJ. 2014;186(2).

9. Sickand M, Cuerden MS, Klarenbach SW, Ojo AO, Parikh CR, Boudville N, et al. Reimbursing live organ donors for incurred non-medical expenses: a global perspective on policies and programs. Am J Transplant. 2009 Dec;9(12):2825-36.

10. Tushla L, Rudow DL, Milton J, Rodrigue JR, Schold JD, Hays R. Living-Donor Kidney Transplantation: Reducing Financial Barriers to Live Kidney Donation-Recommendations from a Consensus Conference. Clin J Am Soc Nephrol. 2015/05/24. 2015;10(9):1696-702.

11. Hays R, Rodrigue JR, Cohen D, Danovitch G, Matas A, Schold J, et al. Financial Neutrality for Living Organ Donors: Reasoning, Rationale, Definitions, and Implementation Strategies. Am J Transplant. 2016 Jul;16(7):1973-81.

12. Thiessen C, Kim YA, Formica R, Bia M, Kulkarni S. Opting out: confidentiality and availability of an "alibi" for potential living kidney donors in the USA. J Med Ethics. 2015 Jul;41(7):506-10.

13. Gill J, Dong J, Rose C, Johnston O, Landsberg D, Gill J. The effect of race and income on living kidney donation in the United States. J Am Soc Nephrol. 2013/08/31. 2013;24(11):1872-9. 
14. Clayton PA, Saunders JR, McDonald SP, Allen RDM, Pilmore H, Saunder A, et al. RiskFactor Profile of Living Kidney Donors: The Australia and New Zealand Dialysis and Transplant Living Kidney Donor Registry 2004-2012. Transplantation. 2016 Jun;100(6):1278-83.

15. Clarke KS, Klarenbach S, Vlaicu S, Yang RC, Garg AX. Donor Nephrectomy Outcomes Research (DONOR) Network: The direct and indrect economic costs incurred by living kidney donors-- a systematic review. . Nephrol Dial Transpl. 2006;21:1952-60.

16. Revicki DA, Irwin D, Reblando J, Simon GE. The accuracy of self-reported disability days. Med Care. 1994/04/01. 1994;32(4):401-4.

17. Employee Earnings and Hours [Internet]. Available from: http://www.abs.gov.au/ausstats/abs@.nsf/mf/6306.0/

18. Grace BS, Clayton PA, Cass A, McDonald SP. Transplantation rates for living- but not deceased-donor kidneys vary with socioeconomic status in Australia. Kidney Int. 2013 Jan;83(1):138-45.

19. Klarenbach S, Gill JS, Knoll G, Caulfield T, Boudville N, Prasad G V, et al. Donor Nephrectomy Outcomes Research (DONOR) Network: Economic consequences incurred by living kidney donors: a Canadian multi-center prospective study. Am J Transpl. 2014;14:916-22.

20. Dew MA, Myaskovsky L, Steel JL, DiMartini AF. Managing the Psychosocial and Financial Consequences of Living Donation. Curr Transplant reports [Internet]. 2014;1(1):24-34. Available from: http://www.pubmedcentral.nih.gov/articlerender.fcgi?artid=3938191\&tool=pmcentrez\&re ndertype $=$ abstract

21. Jacobs CL, Gross CR, Messersmith EE, Hong BA, Gillespie BW, Hill-Callahan P, et al. Emotional and financial experiences of kidney donors over the past 50 years: The RELIVE study. Clin J Am Soc Nephrol. 2015;10(12):2221-31.

22. Rodrigue JR, Schold JD, Morrissey P, Whiting J, Vella J, Kayler LK, et al. Direct and Indirect Costs Following Living Kidney Donation: Findings From the KDOC Study. Am J Transpl. 2016/02/05. 2016;16(3):869-76.

23. Yang RC, Young A, Nevis IFP, Lee D, Jain AK, Dominic A, et al. Life insurance for living kidney donors: a Canadian undercover investigation. Am J Transplant. 2009 Jul;9(7):1585-90.

24. Lensberg BR, Drummond MF, Danchenko N, Despiégel N, François C. Challenges in measuring and valuing productivity costs, and their relevance in mood disorders. Clin Outcomes Res CEOR [Internet]. 2013 Nov 18;5:565-73. Available from:

http://www.ncbi.nlm.nih.gov/pmc/articles/PMC3836685/ 
This article is protected by copyright. All rights reserved. 


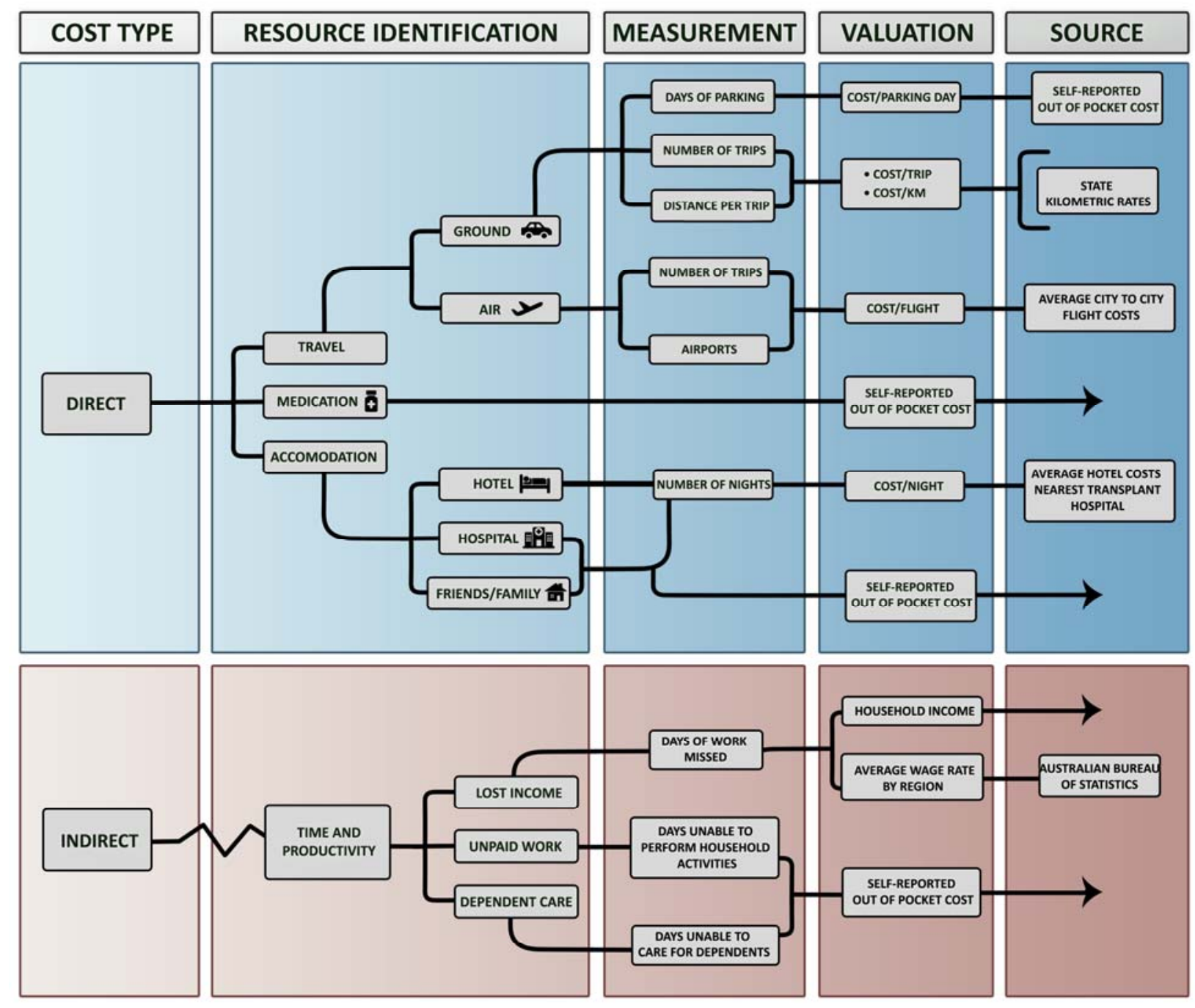




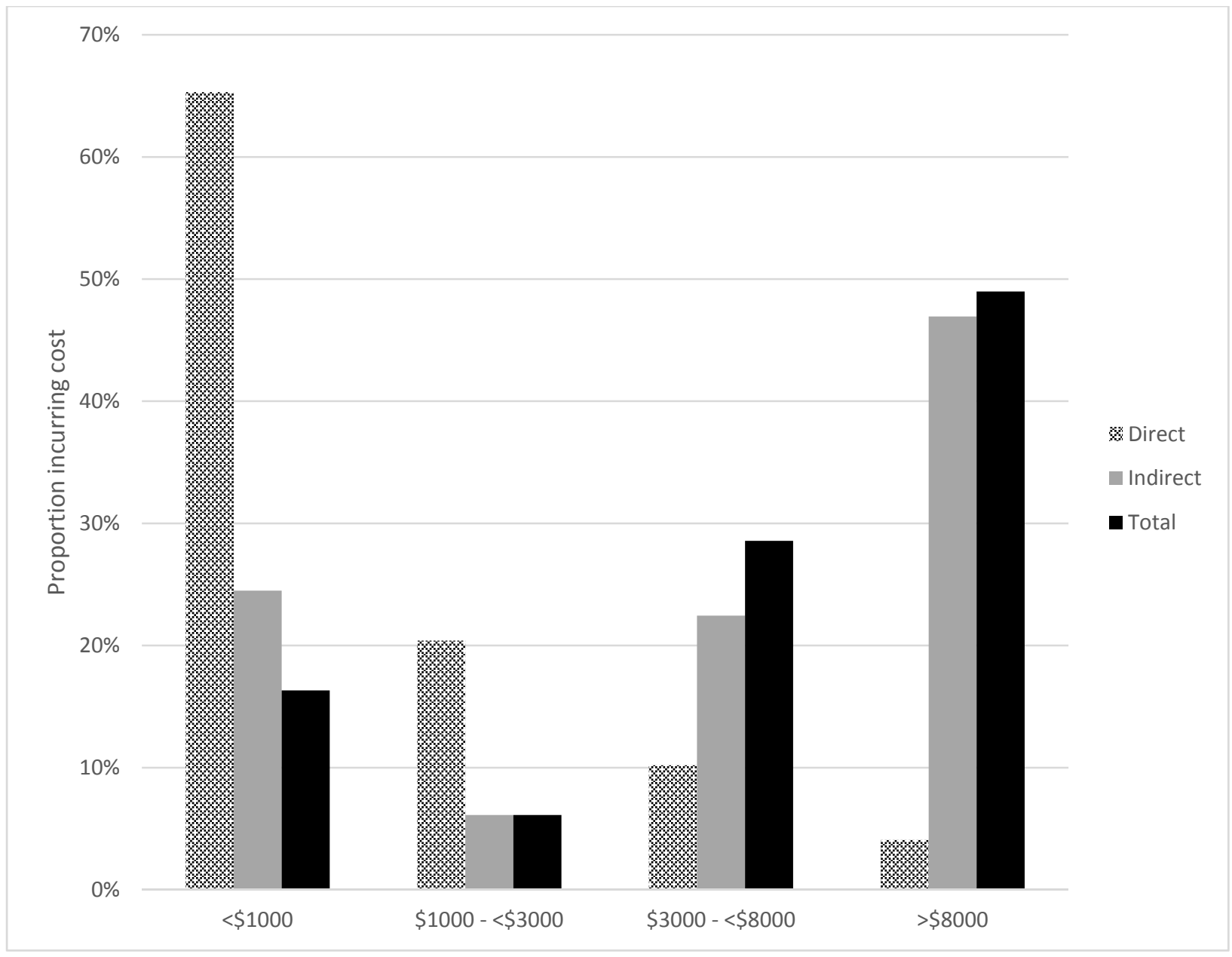

*Twelve donors reported no out of pocket costs for indirect costs. 